\title{
XPS Study of Chemical Changes on the La/Ce Treated Surface of A361 Aluminium Alloy Exposed to Air at Temperatures up to $500^{\circ} \mathrm{C}$
}

\author{
A. Pardo, ${ }^{1}$ S. Feliú Jr., ${ }^{2}$ M. C. Merino, ${ }^{1}$ R. Arrabal, ${ }^{1}$ and E. Matykina $^{3}$ \\ ${ }^{1}$ Departamento de Ciencia de Materiales, Facultad de Ciencias Quimicas, Universidad Complutense, 28040 Madrid, Spain \\ ${ }^{2}$ Centro Nacional de Investigaciones Metalúrgicas CSIC, Avenida. Gregorio del Amo 8, 28040 Madrid, Spain \\ ${ }^{3}$ Corrosion and Protection Centre, School of Materials, The University of Manchester, Sackville Street, P.O. Box 88, \\ Manchester M60 1QD, Spain \\ Correspondence should be addressed to S. Feliú Jr., sfeliu@cenim.csic.es
}

Received 29 September 2009; Accepted 20 December 2009

Recommended by Ming-Xing Zhang

\begin{abstract}
The chemical changes that take place on the rare earth treated surface of the A361 aluminium alloy exposed to air at temperatures between 100 and $500^{\circ} \mathrm{C}$ have been examined using X-ray photoelectron spectroscopy (XPS). The most notable features discussed in this work are the disappearance of $\mathrm{Mg}$ and Si signals at the tested temperatures and disappearance of the Ce signal at temperatures of $400-500^{\circ} \mathrm{C}$. The biphasic microstructure of the A361 alloy, constituted by close to $12 \mathrm{wt} \% \mathrm{Si}$ and the Al matrix, plays an important role in many of the results obtained. The notable growth of aluminium oxide across the conversion coating in the case of the Ce-treated surface is related to the structural transformation experienced by the cerium oxide coating at $400-500^{\circ} \mathrm{C}$.
\end{abstract}

Copyright $\odot 2009$ A. Pardo et al. This is an open access article distributed under the Creative Commons Attribution License, which permits unrestricted use, distribution, and reproduction in any medium, provided the original work is properly cited.

\section{Introduction}

The literature contains many studies on the behaviour of "refractory" alloys in exposure to temperatures of around $900-1000^{\circ} \mathrm{C}$ and the changes that rare earths produce on oxidation kinetics and the properties of the oxide films formed [1-9]. In this respect there has been shown to be a connection between these properties and oxide film growth mechanisms, and in particular the diffusion processes of reacting species $[4,6,10-12]$. In contrast, much less information is available on the oxidation behaviour of aluminium alloys exposed to relatively high temperatures, namely, $400-500^{\circ} \mathrm{C}$, close to the material's melting point.

The present work aims to contribute to knowledge on the processes that take place on the surface of the aforementioned aluminium alloy, treated with La or Ce salts, when exposed to the oxidising action of the environmental atmosphere at temperatures up to $500^{\circ} \mathrm{C}$. Specifically the authors have studied changes in the chemical composition of the surface layer formed on the biphasic alloy A361, trying to relate these changes with changes in the growth mechanisms.
The effect of rare earth conversion coatings applied on the A361 aluminium alloy has been studied by Pardo and their coworkers [13-15]. Following on with this issue, we examine now in greater depth some of the results reported hitherto.

\section{Experimental}

The tested material was A361 aluminium cast alloy (10.5 Si, $0.53 \mathrm{Fe}, 0.1 \mathrm{Cu}, 0.12 \mathrm{Mn}, 0.36 \mathrm{Mg}, 0.11 \mathrm{Zn}$, balance Al). Prior to lanthanide treatments samples were wet ground through successive grades of silicon carbide abrasive papers from P120 to P1200, followed by diamond finishing to $0.1 \mu \mathrm{m}$, rinsed in acetone, and dried. Oxidation was carried out in an airflow laboratory atmosphere.

The optimal conditions for electrodeposition of Cebased coatings on composite rectangular specimens (dimensions: $30 \mathrm{~mm} \times 20 \mathrm{~mm} \times 3 \mathrm{~mm}$ ) were achieved as follows: (a) degreasing with isopropyl alcohol in an ultrasonic bath for 5 minutes at $25^{\circ} \mathrm{C}$; (b) immersion in $75 \%$ ethylene glycol monobutyl ether solution with $2000 \mathrm{ppm} \mathrm{Ce}\left(\mathrm{CeCl}_{3} \cdot 7 \mathrm{H}_{2} \mathrm{O}\right)$ and $1.5 \mathrm{wt} . \% \mathrm{NaCl}$ followed by application of a cathodic 
potential of $3 \mathrm{~V}$ for 10 minutes at $25^{\circ} \mathrm{C}$; (c) rinsing with water and drying at $105^{\circ} \mathrm{C}$. The optimal conditions for electrodeposition of La-based coatings were similar, replacing $2000 \mathrm{ppm} \mathrm{Ce}\left(\mathrm{CeCl}_{3} \cdot 7 \mathrm{H}_{2} \mathrm{O}\right)$ with $2000 \mathrm{ppm} \mathrm{La}$ $\left(\mathrm{LaCl}_{3} \cdot 7 \mathrm{H}_{2} \mathrm{O}\right)$ in the ethylene glycol mono-butyl ether solution [16].

Photoelectron spectra were recorded using a Fisons MT500 spectrometer (XPS) equipped with a hemispherical electron analyser (CLAM 2) and an $\mathrm{Mg} \mathrm{K} \alpha \mathrm{X}$-ray source operated at $300 \mathrm{~W}$. The samples were mechanically fixed on small flat discs supported on an XYZ manipulator placed in the analysis chamber. The residual pressure in this ionpumped analysis chamber was maintained below $10^{-8}$ Torr during data acquisition. The spectra were collected for $20-90$ minutes, depending on the peak intensities at a pass energy of $20 \mathrm{eV}$, which is typical of high-resolution conditions. The intensities were estimated by calculating the area under each peak after smoothing and subtraction of the S-shaped background and fitting the experimental curve to a mix of Lorentzian and Gaussian lines of variable proportion. Although sample charging was observed, accurate binding energies (BEs) could be determined by referencing to the adventitious C 1 s peak at $285.0 \mathrm{eV}$. Atomic ratios were computed from peak intensity ratios and reported atomic sensitivity factors [17]. The XPS analyses were normally repeated two or three times to ensure their reasonable reproducibility. The results are average compositions. The sampled areas were $1 \times 1 \mathrm{~mm}^{2}$.

The thickness of the aluminium oxide layer on the surface of the specimens was determined using the expression given by Strohmeier [18]:

$$
d_{o}(\mathrm{~nm})=\lambda_{\text {oxide }} \sin \theta \ln \left[\frac{\mathrm{I}_{\text {oxide }} \times \lambda_{\text {metal }} \times \mathrm{N}_{\text {metal }}}{\mathrm{I}_{\text {metal }} \times \lambda_{\text {oxide }} \times \mathrm{N}_{\text {oxide }}}+1\right],
$$

where $d_{o}$ is the thickness of the aluminium oxide layer (in $\mathrm{nm}) ; \theta$ is the photoelectron output angle; $\mathrm{I}_{\text {oxide }}$ and $\mathrm{I}_{\text {metal }}$ are the intensity of the aluminium components in metallic state and as oxide on the Al2p peak; $\lambda_{\text {metal }}$ and $\lambda_{\text {oxide }}$ are the mean free path of photoelectrons in the substrate and the oxide layer; and $\mathrm{N}_{\text {metal }}$ and $\mathrm{N}_{\text {oxide }}$ are the volume densities of aluminium atoms in metal and oxide [19]. The $\lambda_{\text {metal }}$ and $\lambda_{\text {oxide }}$ are 2.2 and $2.4 \mathrm{~nm}$, respectively, and an $\mathrm{N}_{\text {metal }} / \mathrm{N}_{\text {oxide }}$ ratio of 1.5 was used [18].

\section{Results and Discussion}

3.1. General Tendencies and Effect of the Microstructure. Besides the notable presence of $\mathrm{Al}$ and $\mathrm{O}$ signals at all the oxidation temperatures (Figure 1), XPS analysis of the surface of the untreated A361 alloy has revealed the presence of Si and Mg alloying elements. The intensity of the Si signal shows a clear tendency to decrease with the temperature below $300^{\circ} \mathrm{C}$, while the $\mathrm{Mg}$ signal only appears above around $400^{\circ} \mathrm{C}$, becoming especially relevant at $500^{\circ} \mathrm{C}$ (Figures 1 and 2).

Like the untreated surface, the surface of the A361 alloy treated with $\mathrm{La}$ or Ce solutions shows both $\mathrm{O}$ and $\mathrm{Al}$ signals but accompanied in this case by the La signal

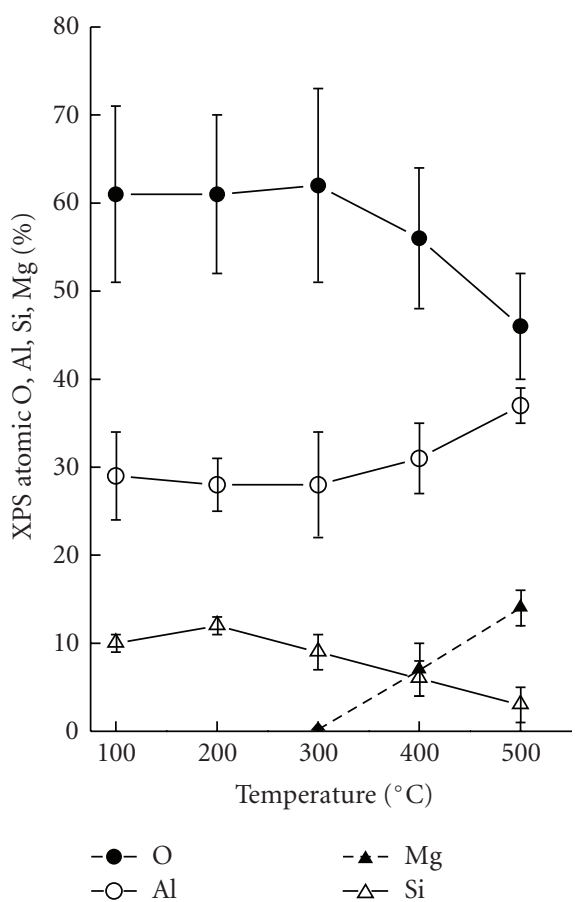

FIGURE 1: Evolution of composition with temperature for the untreated A361 surface.

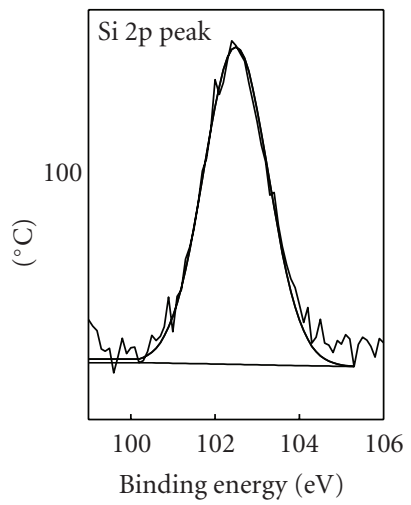

(a)

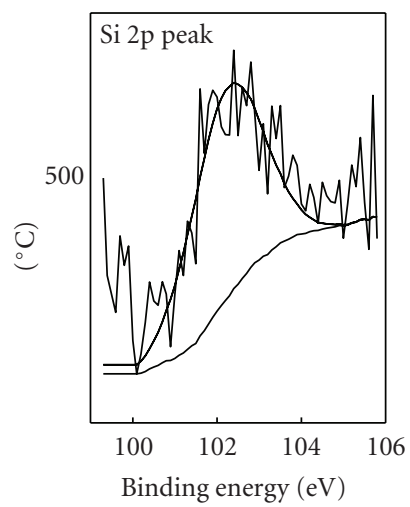

(c)

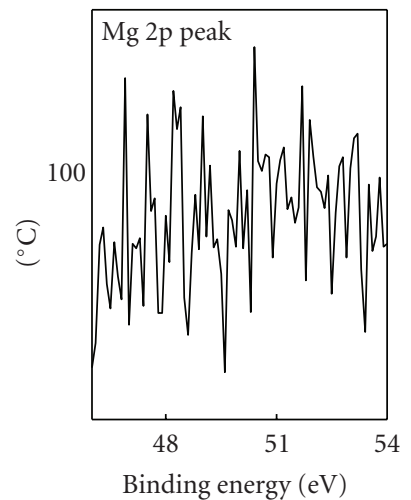

(b)

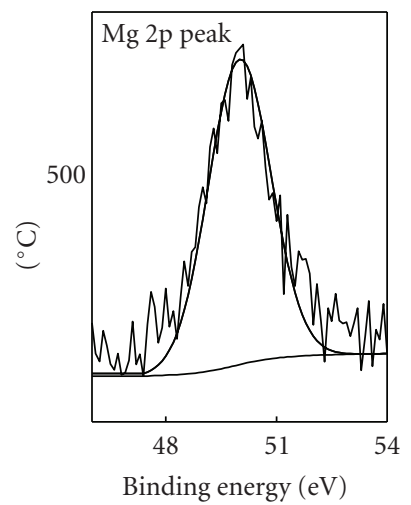

(d)
FIGURE 2: Effect of temperature on weakening of the Si signal and appearance of the $\mathrm{Mg}$ signal on the untreated A361 surface. 


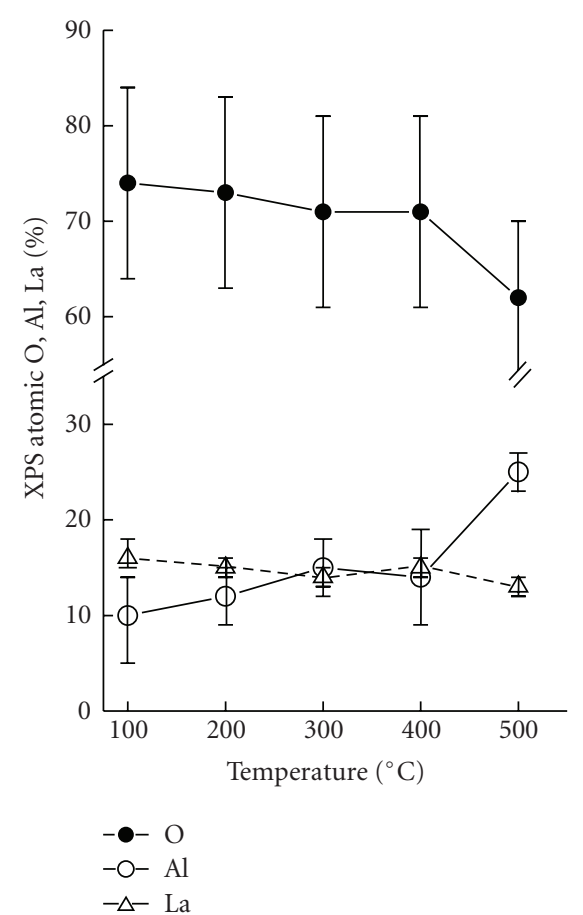

FIGURE 3: Evolution of composition with temperature for the Latreated surface.

at all temperatures (Figure 3 ), or by the $\mathrm{Ce}$ signal at all temperatures except $500^{\circ} \mathrm{C}$ (Figures 4 and 5). On the other hand, conversion treatment leads to the complete disappearance of the Si signal at all the tested temperatures, which is explained by the fact that the conversion coating is built on the Si phase of this biphasic alloy [13-16]. The $\mathrm{Mg}$ signal is also seen to be totally absent, even at 400$500^{\circ} \mathrm{C}$, temperatures at which the signal of this element had appeared on the untreated surface.

According to the above results, the following features are worthy of discussion: (i) the appearance of the $\mathrm{Mg}$ signal on the untreated A361 alloy at $400-500^{\circ} \mathrm{C}$; (ii) the disappearance of the $\mathrm{Mg}$ and $\mathrm{Si}$ signals at all the temperatures on the treated A361 alloy; (iii) the disappearance of the Ce signal and weakening of the La signal on the treated A361 alloy at temperatures of $400-500^{\circ} \mathrm{C}$.

Among the factors that probably influence the results it is necessary to consider the microstructure of the A361 alloy, with close to $12 \%$ of its surface constituted by practically pure Si (proeutectic and eutectic) and the rest by an also practically pure Al matrix [13]. These two phases behave in different ways, both during the process of formation of the conversion coating on the metal surface and during subsequent oxidation of the A361 alloy at high temperature. As has been shown in the previous work [13-15], the deposition of rare earth elements on the A361 alloy tends to take place on surface areas corresponding to the Al-Si eutectic and primary Si precipitates, which leads to an unequal response of different points of the surface to the oxidising action of the atmosphere. Images of the heterogeneous nature

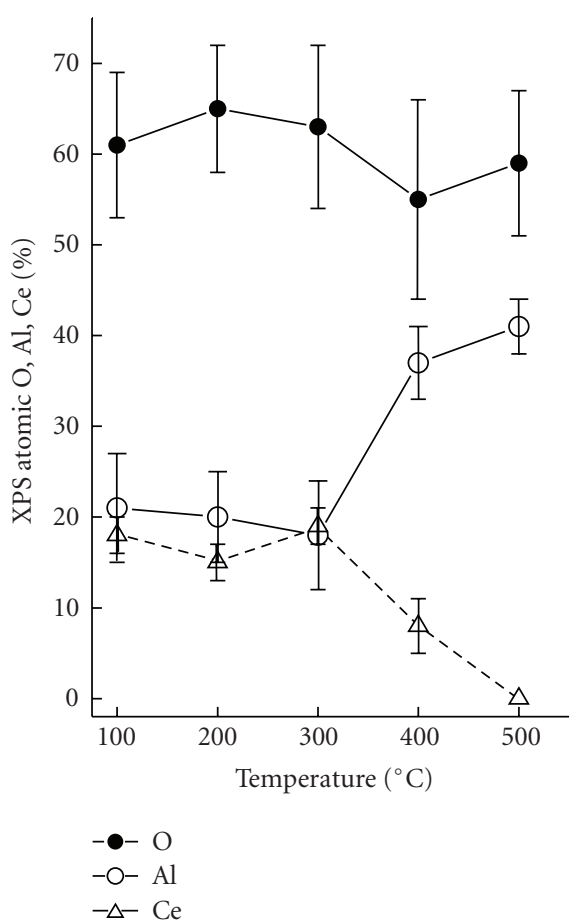

FIGURE 4: Evolution of composition with temperature for the Cetreated surface.

of the deposits of cerium and lanthanum oxides on the surface of A361 and other Al-Si materials can be seen in earlier papers by Pardo et al. [20-22]. The $\mathrm{Al}_{2} \mathrm{O}_{3}$ film will therefore preferentially grow on the $\alpha$-Al phase areas which are apparently not protected by the conversion coating; as will be seen below, a certain degree of aluminium oxidation below the conversion coating cannot be ruled out as the coating is not completely impermeable to oxygen.

3.2. Bare Surface. Considerable $\mathrm{Mg}$ enrichment of the outermost surface of the untreated A361 alloy has been found at $400-500^{\circ} \mathrm{C}$ (Figure 6), as shown, for instance, by the $\mathrm{Mg} / \mathrm{Al}$ atomic ratio value of 0.4 on the A361 surface at $500^{\circ} \mathrm{C}$ compared to the value of $4 \times 10^{-3}$ for the bulk alloy composition.

The major driving force for $\mathrm{Mg}$ segregation seems to be the formation of magnesium oxide by reaction with the air $[12,23,24]$. The effect is related with the different heats of formation of aluminium and magnesium oxides, with the latter being favoured. The activation energy for diffusion is also lower for $\mathrm{Mg}$ than for $\mathrm{Al}[12,23-25]$. As a result, the oxide film formed at high temperature on the surface of $\mathrm{Mg}$ containing aluminium alloys soon becomes $\mathrm{Mg}$ enriched. In contrast, at room temperature an amorphous $\mathrm{Al}_{2} \mathrm{O}_{3}$ film is formed on the alloy surface and acts as a barrier, preventing the diffusion of a large amount of $\mathrm{Mg}$ through it [3, 12, 23-26]. When this film is heated above $350-400^{\circ} \mathrm{C}$, the $\mathrm{Al}_{2} \mathrm{O}_{3}$ attains partial crystallisation [27], which allows $\mathrm{Mg}$ to diffuse through the film towards the oxide/gas interface, and therefore its oxidation in the outer part of the film 


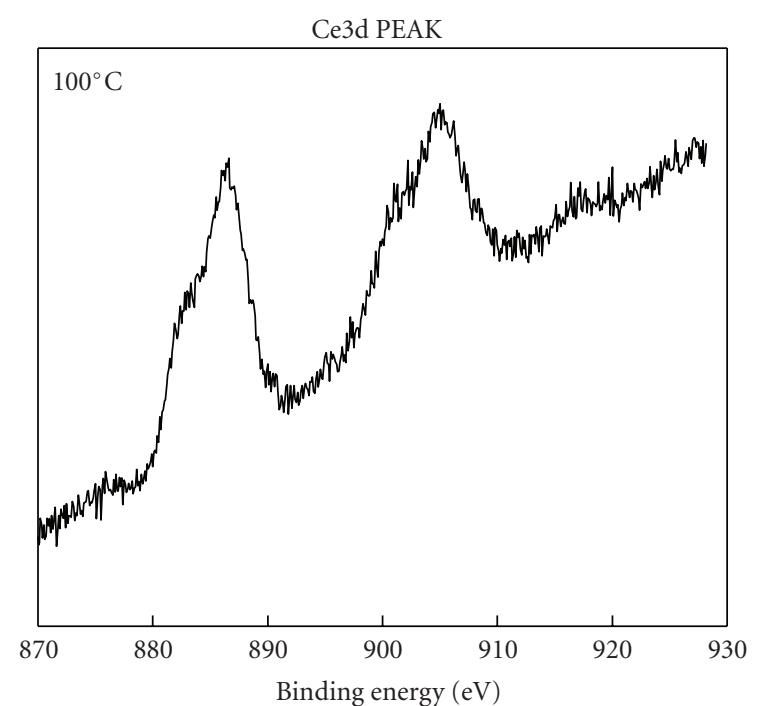

(a)

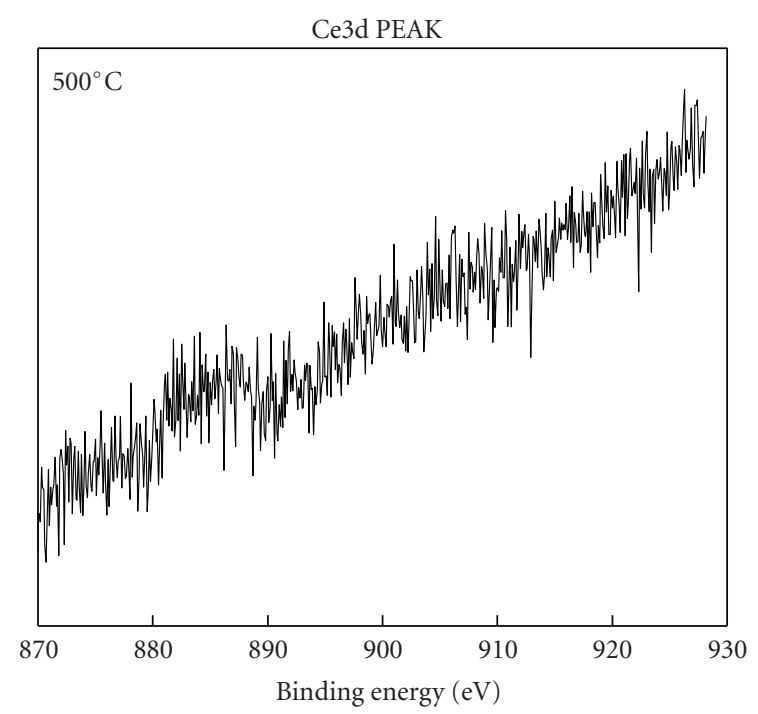

(b)

Figure 5: Complete disappearance of the cerium signal on the Cetreated A361 surface.

[4]. Crystallised alumina grain boundaries, or interphase boundaries between the crystalline and amorphous $\mathrm{Al}_{2} \mathrm{O}_{3}$, may act as diffusion short-circuits $[2,26,27]$. The presence of $\mathrm{MgAl}_{2} \mathrm{O}_{4}$ in the oxide film has also been related with much faster diffusion of $\mathrm{Mg}$ ions through the $\mathrm{Al}_{2} \mathrm{O}_{3}$ compared to $\mathrm{Al}$ and $\mathrm{Si}$ ions [26].

As illustrated in Figure 6, a value of $\sim 0.35$ has been found for the $\mathrm{Si} / \mathrm{Al}$ atomic ratio on the surface of the $\mathrm{A} 361$ alloy heated in the air at temperatures between 100 and $300^{\circ} \mathrm{C}$. This ratio decreases at higher temperatures until becoming practically equal at $500^{\circ} \mathrm{C}$ (bulk atomic ratio $\sim 0.1$ ). Therefore, the degree of Si enrichment of the A361 alloy surface is very moderate throughout the studied temperature range. The weakening of the Si signal in the $400-500^{\circ} \mathrm{C}$ range may be due to lateral extension (beyond the boundary with

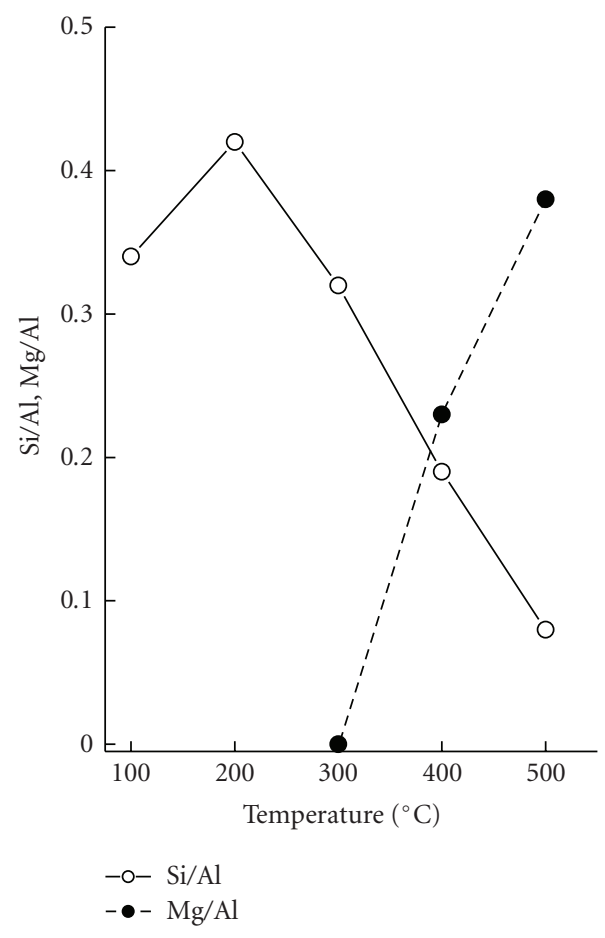

FIGURE 6: Variation of $\mathrm{Mg} / \mathrm{Al}$ and $\mathrm{Si} / \mathrm{Al}$ ratios with the temperature for the untreated surface.

the $\mathrm{Si}$ phase) of the $\mathrm{Al}_{2} \mathrm{O}_{3}$ film which grows from the $\alpha$ $\mathrm{Al}$ matrix, a phenomenon that will become more evident as the temperature rises. $\mathrm{Mg}$ diffusion via the boundaries between the $\mathrm{Si}$ and $\alpha$-Al phases [26] may also contribute to the concealment of the Si signal.

3.3. La and Ce Treated Surfaces. Treatment of the A361 alloy with $\mathrm{La}$ or Ce salt solutions leads to the formation of a nonhomogeneous surface consisting of large patches or islands of rare earth oxide together with portions of apparently clean metal. The rare earth islands are about $300 \mathrm{~nm}$ thick and are mainly located over the Si phase and the Al-Si eutectic colonies [13]. According to XPS measurements the proportion of the surface occupied by rare earth atoms is of the order of $40-60 \%$. The rest of the surface $(\alpha-\mathrm{Al}$ phase) is covered by a $\mathrm{Al}_{2} \mathrm{O}_{3}$ film of just a few nanometres in thickness, for example around $4-8 \mathrm{~nm}$, depending on the oxidation temperature [13].

Besides being the basic component of the conversion coating islands that spread across the A361 alloy surface, the $\mathrm{La}$ and Ce ions must also be present in a small proportion on the remaining $\alpha$-Al phase areas apparently unaffected by the conversion coating, in this case as an impurity (or dopant) in the thin aluminium oxide film that grows on the $\alpha$-Al phase. In research on oxide formation on aluminium alloys in boiling $\mathrm{CeCl}_{3}$ solution, Gorman et al. [28] reported some incorporation of Ce ions into the $\mathrm{Al}_{2} \mathrm{O}_{3}$ of the order of 1 at $\% \mathrm{Ce}$.

XPS data for the rare earth treated A361 surfaces (Figures 3 and 4) shows the complete disappearance of the Si signal, despite the fact that this alloying element constitutes 12 at $\%$ 
of the bulk alloy. This is explained by considering that the conversion coating is built on the $\mathrm{Si}$ rich areas, which it thereby isolates, and so this element goes unnoticed.

The presence of $\mathrm{Mg}$ is also not to be expected on the surface areas protected by the thick islands of rare earth precipitates. However, $\mathrm{Mg}$ should at least be detected (as in the aforementioned case of the bare surface) at $400-500^{\circ} \mathrm{C}$ on the portions of the surface that the conversion coating leaves unprotected. For this reason the complete absence of any $\mathrm{Mg}$ signal at these temperatures suggests a radical change in the way the $\mathrm{Al}_{2} \mathrm{O}_{3}$ film thickens. One hypothesis is that the presence of small amounts of rare earth ions dissolved in the $\mathrm{Al}_{2} \mathrm{O}_{3}$ film lattice prevents diffusion of $\mathrm{Mg}$ ions from the inner oxide interface to the outer oxide-air interface by blocking the short-circuit diffusion paths in the $\mathrm{Al}_{2} \mathrm{O}_{3}$ oxide $[3,4,12,23-26,29]$.

3.4. Weakening of the La Signal and Disappearance of the Ce Signal. XPS analysis of the treated A361 surface oxidised at $400-500^{\circ} \mathrm{C}$ shows a weakening of the La signal on the La treated surface (Figure 3 ) and the complete disappearance of the Ce signal on the Ce treated surface (Figures 4 and 5). This phenomenon is explained by the growth of aluminium oxide across the rare earth conversion coating.

The presence of $\mathrm{Al}_{2} \mathrm{O}_{3}$ on the outermost surface of the conversion coating strongly suggests that the oxidation process on the coated A361 alloy takes place mostly due to outward $\mathrm{Al}$ diffusion from the alloy-oxide interface and not to the inward diffusion of oxygen from the oxide-air interface. Figure 7 shows schematically how the diffusion of aluminium cations and the migration of electrons explains the appearance of $\mathrm{Al}_{2} \mathrm{O}_{3}$ on the outermost surface of the rare earth coating, which is in contact with the air; line and planar defects in the oxide form channels or conduits through which species diffuse rapidly (short circuit diffusion). The $\mathrm{Al}^{3+}$ ions can move along the interfaces present in the La or Ce oxide layers which run from the alloy film interface to the outer film surface.

The importance of the process of aluminium growth and extension on the rare earth treated surfaces has been quantified in the $100-500^{\circ} \mathrm{C}$ temperature range by means of the $\mathrm{RE} / \mathrm{Al}$ XPS atomic ratio between the surface concentration of rare earths (REs) and aluminium. Figure 8 shows that the $\mathrm{RE} / \mathrm{Al}$ ratio tends to decrease as the temperature rises, above all in the case of the Ce conversion coatings, where at $500^{\circ} \mathrm{C}$ the ratio is practically zero. Thus the permeation of the conversion coating by $\mathrm{Al}^{3+}$ ions from oxidation of the substrate, and the growth from them of the $\mathrm{Al}_{2} \mathrm{O}_{3}$ film on the outer surface of the coating, seems to take place much more quickly in on the Ce treated surface than on the La treated surface of the A361 alloy.

The aforementioned difference in behaviour between the two rare earths is most likely due to the structural transformation experienced by the cerium oxide at $400-500^{\circ} \mathrm{C}$ since the valence of cerium changes at this temperature from trivalent to tetravalent, a change that does not take place in the case of $\mathrm{La}$, which remains trivalent throughout the tested temperature range. It may be imagined that the change

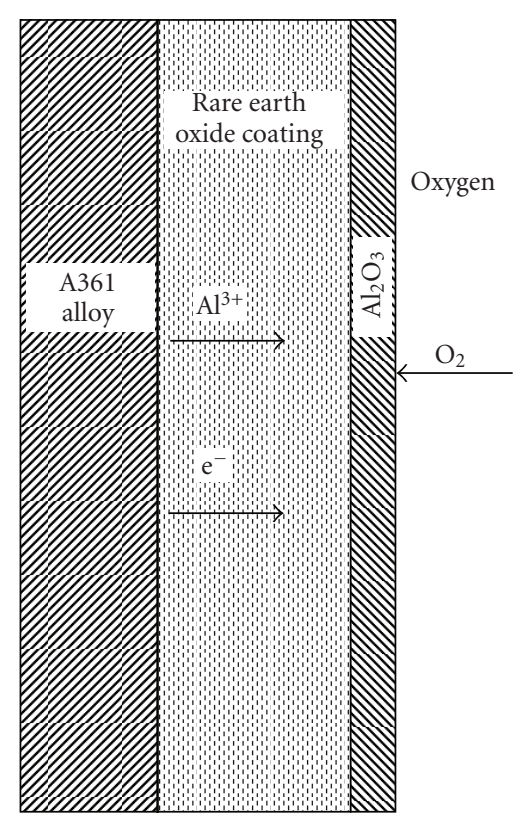

FIGURE 7: Scheme of transport of reacting species in the formation of the $\mathrm{Al}_{2} \mathrm{O}_{3}$ film on the rare earth oxide coating.

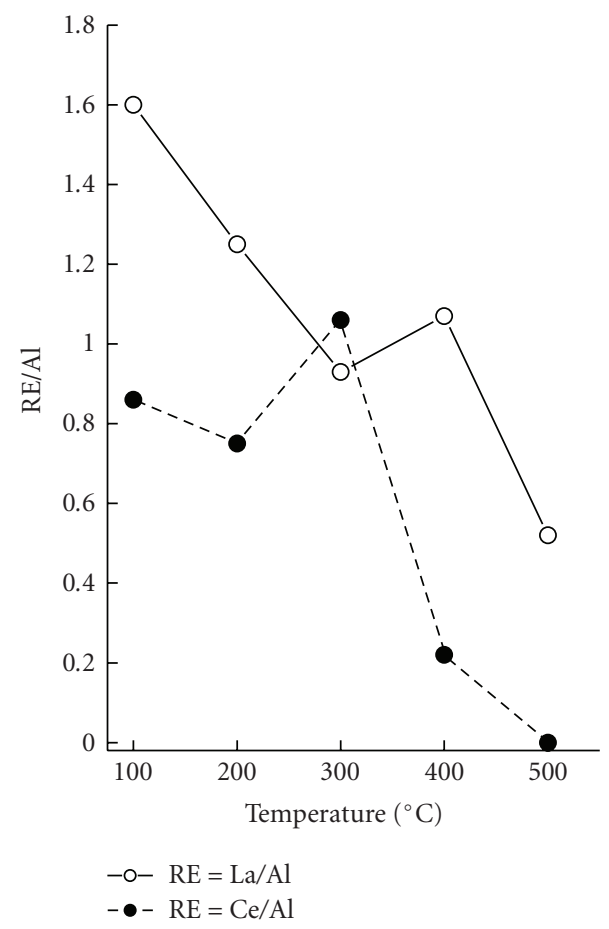

Figure 8: Variation of $\mathrm{La} / \mathrm{Al}$ and $\mathrm{Ce} / \mathrm{Al}$ ratios with temperature for the treated surfaces.

of valence transforms the oxide into a more defective and open structure, causing greater diffusion of $\mathrm{Al}^{3+}$ ions via microcapillaries in the oxide [28]. 


\section{Conclusions}

(1) XPS analysis of the A361 alloy surface oxidised in air at several temperatures shows important changes in the chemical composition of the surfaces treated with lanthanum or cerium salts, depending on the oxidation temperature and the nature of the conversion coating applied.

(2) Notable features include the disappearance of the $\mathrm{Mg}$ signal on the La or Ce treated surfaces and its presence on the untreated surface oxidised at 400$500^{\circ} \mathrm{C}$. It is also notable that the Si signal disappears at all the tested temperatures, and that the La signal is weakened and the Ce signal completely disappears at $400-500^{\circ} \mathrm{C}$.

(3) The changes in the surface chemistry have been related with changes in the $\mathrm{Al}_{2} \mathrm{O}_{3}$ film growth mechanism, which can proceed unevenly on the different microstructural areas of the alloy.

(4) The behaviour of the cerium treated surface at $400-500^{\circ} \mathrm{C}$ stands out due to the transformation experienced by cerium oxide at these temperatures, as the valence of cerium changes from trivalent to tetravalent.

\section{Acknowledgment}

The authors are grateful to the MCYT (Project MAT 200913530).

\section{References}

[1] D. P. Whittle and J. Stringer, "Improvements in hightemperature oxidation resistance by additions of reactive elements or oxide dispersions," Philosophical Transactions of the Royal Society of A, vol. 295, no. 1413, pp. 309-329, 1990.

[2] J. Stringer, "The reactive element effect in high-temperature corrosion," Materials Science and Engineering A, vol. 120-121, pp. 129-137, 1989.

[3] R. J. Hussey, P. Papaiacovou, J. Shen, D. F. Mitchell, and M. J. Graham, "The effect of ceria coatings on the high-temperature oxidation of iron-chromium alloys," Materials Science and Engineering A, vol. 120-121, pp. 147-151, 1989.

[4] R. Thanneeru, S. Patil, S. Deshpande, and S. Seal, "Effect of trivalent rare earth dopants in nanocrystalline ceria coatings for high-temperature oxidation resistance," Acta Materialia, vol. 55, no. 10, pp. 3457-3466, 2007.

[5] V. Viswanathan, R. Filmalter, S. Patil, S. Deshpande, and S. Seal, "High-temperature oxidation behavior of solution precursor plasma sprayed nanoceria coating on martensitic steels," Journal of the American Ceramic Society, vol. 90, no. 3, pp. 870-877, 2007.

[6] S. Patil, S. C. Kuiry, and S. Seal, "Nanocrystalline ceria imparts better high-temperature protection," Proceedings of the Royal Society A, vol. 460, no. 2052, pp. 3569-3587, 2004.

[7] H. J. Grabke, "Surface and interface segregation in the oxidation of metals," Surface and Interface Analysis, vol. 30, no. 1, pp. 112-119, 2000.

[8] F. Czerwinski, G. I. Sproule, M. J. Graham, and W. W. Smeltzer, "An ${ }^{18} \mathrm{O}$-SIMS study of oxide growth on nickel modified with $\mathrm{Ce}$ implants and $\mathrm{CeO}_{2}$ coatings," Corrosion Science, vol. 37, no. 4, pp. 541-556, 1995.

[9] L. V. Ramanathan, "Role of rare-earth elements on high temperature oxidation behavior of $\mathrm{FeCr}, \mathrm{NiCr}$ and $\mathrm{NiCrAl}$ alloys," Corrosion Science, vol. 35, no. 5-8, pp. 871-875, 1993.

[10] N. A. Braaten, J. K. Grepstad, and S. Raaen, "Effects of thin cerium overlayers on the oxidation of tantalum and aluminium," Surface Science, vol. 222, no. 2-3, pp. 499-516, 1989.

[11] C. Ocal, B. Basurco, and S. Ferrer, "An ISS-XPS study on the oxidation of $\mathrm{Al}(111)$; identification of stoichiometric and reduced oxide surfaces," Surface Science, vol. 157, no. 1, pp. 233-243, 1985.

[12] C. Lea and J. Ball, "The oxidation of rolled and heat treated Al-Mg alloys," Applications of Surface Science, vol. 17, no. 3, pp. 344-362, 1984.

[13] A. Pardo, S. Feliu Jr., M. C. Merino, R. Arrabal, and E. Matykina, "The effect of cerium and lanthanum surface treatments on early stages of oxidation of A361 aluminium alloy at high temperature," Applied Surface Science, vol. 254, no. 2, pp. 586-595, 2007.

[14] A. Pardo, M. C. Merino, R. Arrabal, S. Feliu Jr., and F. Viejo, "Oxidation behaviour of cast aluminium matrix composites with Ce surface coatings," Corrosion Science, vol. 49, no. 7, pp. 3118-3133, 2007.

[15] A. Pardo, M. C. Merino, R. Arrabal, and S. Feliu Jr., "Effect of La surface coatings on oxidation behavior of aluminum alloy/SiCp composites," Oxidation of Metals, vol. 67, no. 1-2, pp. 67-86, 2007.

[16] A. Pardo, M. C. Merino, R. Arrabal, F. Viejo, and J. A. Muñoz, "Ce conversion and electrolysis surface treatments applied to A3xx.x alloys and A3xx.x/SiCp composites," Applied Surface Science, vol. 253, no. 6, pp. 3334-3344, 2007.

[17] C. D. Wagner, L. E. Davis, M. V. Zeller, J. A. Taylor, R. H. Raymond, and L. H. Gale, "Empirical atomic sensitivity factors for quantitative-analysis by electron-spectroscopy for chemical-analysis," Surface and Interface Analysis, vol. 3, no. 5, pp. 211-225, 1981.

[18] B. R. Strohmeier, "ESCA method for determining the oxide thickness on aluminum alloys," Surface and Interface Analysis, vol. 15 , no. 1 , pp. $51-56,1990$.

[19] C. Chen, S. J. Splinter, T. Do, and N. S. McIntyre, "Measurement of oxide film growth on $\mathrm{Mg}$ and $\mathrm{Al}$ surfaces over extended periods using XPS," Surface Science, vol. 382, no. 1-3, pp. L652-L657, 1997.

[20] A. Pardo, M. C. Merino, R. Arrabal, S. Merino, F. Viejo, and M. Carboneras, "Effect of Ce surface treatments on corrosion resistance of A3xx.x/SiCp composites in salt fog," Surface and Coatings Technology, vol. 200, no. 9, pp. 2938-2947, 2006.

[21] A. Pardo, M. C. Merino, R. Arrabal, S. Merino, F. Viejo, and A. E. Coy, "Effect of la surface treatments on corrosion resistance of A3xx.x/SiCp composites in salt fog," Applied Surface Science, vol. 252, no. 8, pp. 2794-2805, 2006.

[22] A. Pardo, M. C. Merino, R. Arrabal, S. Feliu Jr., F. Viejo, and M. Carboneras, "Enhanced corrosion resistance of A3xx.x/SiCp composites in chloride media by La surface treatments," Electrochimica Acta, vol. 51, no. 21, pp. 4367-4378, 2006.

[23] C. R. Werrett, D. R. Pyke, and A. K. Bhattacharya, "XPS studies of oxide growth and segregation in aluminium-silicon alloys," Surface and Interface Analysis, vol. 25, no. 10, pp. 809-816, 1997.

[24] B. Goldstein and J. Dresner, "Growth of MgO films with high secondary electron emission on Al-Mg alloys," Surface Science, vol. 71, no. 1, pp. 15-26, 1978. 
[25] S. O. Saied and J. L. Sullivan, "A study of thermally induced segregation of magnesium in aluminium-magnesium alloys by means of AES," Journal of Physics: Condensed Matter, vol. 5, no. 33, pp. A165-A166, 1993.

[26] A. Nylund, K. Mizuno, and I. Olefjord, "Influence of Mg and Si on the oxidation of aluminum," Oxidation of Metals, vol. 50, no. 3-4, pp. 309-325, 1998.

[27] S. Scotto-Sheriff, E. Darque-Ceretti, G. Plassart, and M. Aucouturier, "Physico-chemical characterisation of native airformed oxide films on $\mathrm{Al}-\mathrm{Mg}$ alloys at low temperature. Influence of water," Journal of Materials Science, vol. 34, no. 20, pp. 5081-5088, 1999.

[28] J. D. Gorman, A. E. Hughes, D. Jamieson, and P. K. J. Paterson, "Oxide formation on aluminum alloys in boiling deionised water and $\mathrm{NaCl}, \mathrm{CeCl}_{3}$ and $\mathrm{CrCl}_{3}$ solutions," Corrosion Science, vol. 45, no. 6, pp. 1103-1124, 2003.

[29] G. M. Ecer, R. B. Singh, and G. H. Meier, "The influence of superficially applied oxide powders on the high-temperature oxidation behavior of $\mathrm{Cr}_{2} \mathrm{O}_{3}$-forming alloys," Oxidation of Metals, vol. 18, no. 1-2, pp. 55-81, 1982. 

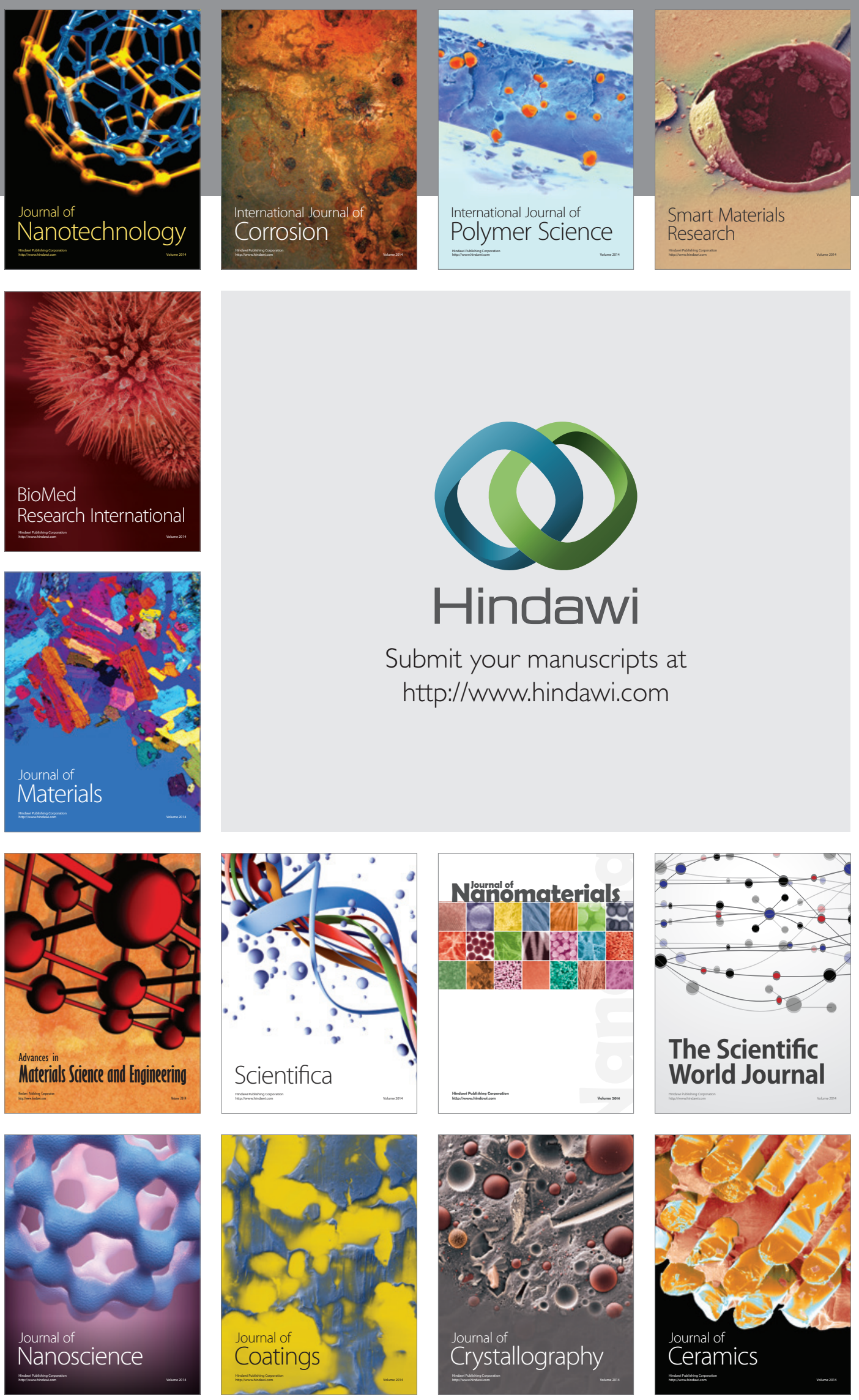

The Scientific World Journal

Submit your manuscripts at

http://www.hindawi.com

\section{World Journal}

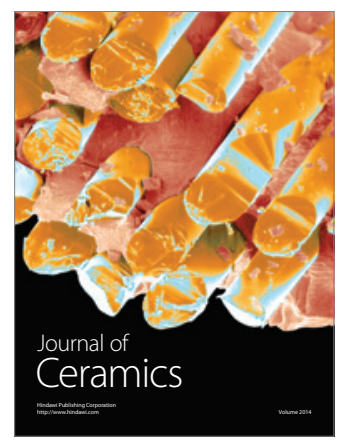

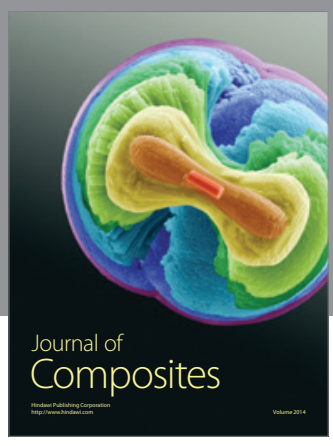
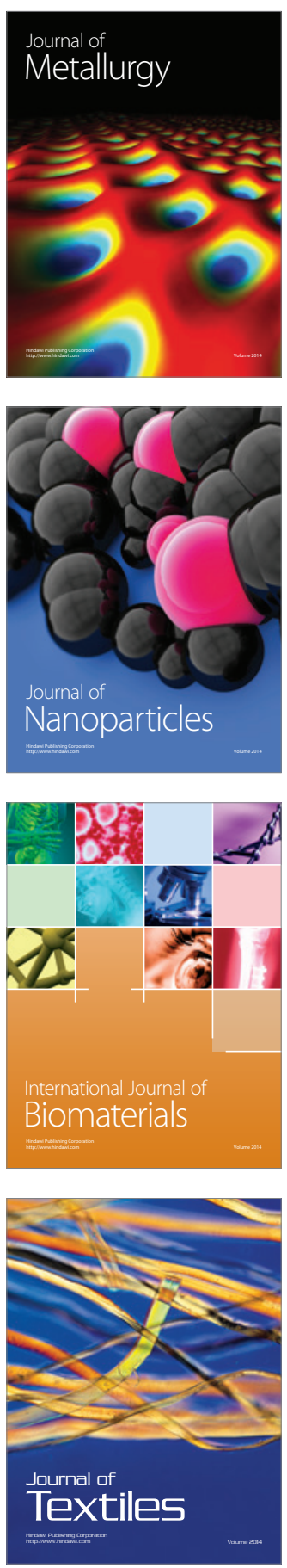